\title{
Internet Addiction, Locus of Control and Resilience
}

\author{
Juslin Jacob*
}

\section{Abstract}

The study investigates the difference in the Locus of Control and Resilience with respect to different levels of Internet Addiction as well as their impact on Internet Addiction among emerging adults. It assesses Internet Addiction levels, investigates the association between Internet Addiction, Locus of Control and Resilience and analyses gender difference. Internet Addiction Test by Young, Locus of Control (LOC-Scale) Scale developed by Rotter (1966) and The Brief Resilience Scale were used. Pearson's product-moment correlation analysis was used to evaluate the association between Internet Addiction, Locus of Control and Resilience. An independent t-test was used to test whether there is a statistical difference between gender and internet addiction at different levels. One-way ANOVA was used to investigate the gender difference in Internet Addiction, Locus of Control and Resilience respectively. The research findings show that there is a significant relationship between Internet Addiction, Locus of Control and Resilience as well as significant gender difference in Internet Addiction. A significant difference in Resilience among the different levels of Internet Addiction was also found in the study.

Keywords: Internet Addiction, Locus of Control, Resilience

\section{Introduction}

The internet has turned out to be progressively essential to presentday grown-ups. According to Anthony Turner (Turner, 2015), this

* Kristu Jayanti College (Autonomous), Bangalore, India; j.jacob2330@gmail.com 
generation has a digital bond with the internet. As indicated by Pastor (2001), among the internet-using population, people between the age groups of 18 and 34 are the most active users (Rotsztein, 2003). Students going to college constitute a significant portion of the development. Frequent internet usage has particularly become a serious concern in society and a genuine worry among mental health professionals.

The concept of the Internet arose with the phrase "Internet Connection Network" (Greenfield, 1999) which connected computers systems around the globe through the use of a conventional protocol (Tukaram, 2017). The internet is increasingly changing and being shaped by users and their lifestyles (Miller \& Slater, 2001).

According to the Global Internet Statistics for 2018 by We Are Social blog ("Digital in 2018," 2018), there were more than 4.1 billion internet users worldwide. A rapid growth of $7 \%$ since the previous yearhas been noted. Not only is the expansion in average users evident but also the measure of time spent on the internet has gone up in the past 12 months to 6 hours per day. Two-thirds of the world population has mobile phones making it much easier to access the internet (Kujawski, 2018).

The concept of "addiction" evolved from "addicere" in Latin, which implies "bound to" or "enslaved by" (Potenza, 2006). The addiction as a notion was initially used as a non- specific reference to distinct social behaviours, referring to the state of being "given" or involved intensively in any activity (Alexander \& Schweighofer, 1988). Addiction is conventionally portrayed as a status of physical and psychological dependence on psychoactive substances such as heroin, alcohol, tobacco and other drugs. As referenced by Mahadevaswamy (2017), a number of psychology experts presently describe addiction as "including abnormal psychological dependence on multiple items, such as gambling, computers, internet, food, sex, pornography, workout, work, watching TV or certain kinds of non-pornographic videos, religious obsession, squeezing with shopping" (Morrissey, Keogh, \& Doyle, 2008). 


\section{Internet-Addiction}

As shown by statistics, individuals spend much more time on the internet than on anything else in their everyday routine. This compulsive use has gained recognition among health practitioners and the term "Internet Addiction" has come into existence. The expression "Internet addiction", created by Dr Ivan Goldberg in 1995, was primarily used to illustrate the impact of unreasonably increased internet use on personal lives. Unlike drugs or alcohol consumption, Internet Addiction is an impulse controlled. Using the internet excessively to an extent that it meddles with daily lives is identified as Internet Addiction Disorder also known as Problematic Internet Use (PIU) and Pathological Internet Use.

As explained by Kandell (1998) "Internet Addiction Disorderis a psychological dependence on the Internet characterised by increasing investment of resources on internet-related activities, unpleasant feelings when off-line, an increasing tolerance to the effects of being online, and denial of the problematic behaviors"(Kandell,1998). It is presumed that the distinctive characteristics of the internet, such as the speed of the internet, accessibility to it, intensity and stimulation of its content contribute to Internet Addiction (Greenfield, 1999). As rightly mentioned by Beard in 2002, "internet addiction is an explanation for uncontrollable, damaging use of this technology and it is a warning sign that a person is having difficulty controlling his or her internet use" (Beard, 2002). Further research studies by Young in 2011, defined "Internet addiction as any online-related, compulsive behavior which interferes with normal living and causes severe stress on family, friends, loved ones, along with one's work environment."

Griffiths proposed seven particular areas for Internet Addiction: “(a) forbearance, (b) spending more time than intended on the Internet, (c) spend most of their time in practices that allow them to be online, (d) spending more time on line than in social or recreational activities, (e) continuing use despite work, academic, economic or family concerns, (f) failed attempts to stop or reduce use of the Internet and (g) withdrawal"(Griffiths, 1998). According 
to this author, the diagnosis should be made in the presence of three or more of the areas described.

Young (1999) classified Internet Addiction into five specific subtypes (Shaw \& Black, 2008) which include:

1. Cybersex Addiction: thisincludes internet pornography, adult fantasy chat rooms, and other online sexual activities.

2. Computer Addiction: thishappens when an individual actually uses the computerexcessively for offline activities which may include pre-programmed games.

3. Addiction to Cyber Relationships: this occurs when people get overly engaged in online relationships and may even indulge in online infidelity. They may reach a point where they supplant online social relationships to genuine ties with their lovedones.

4. Informational Addiction: thisoccurs when people constantly look up information on various search engines which may lead to information overload.

5. Online Compulsions: thisincorporates a broad variety of behaviour such as online gambling, stock trading or even shopping from various websites.

\subsection{Effects of Internet Addiction}

Internet Addiction causes private, family, financial, academic, vocational, as well as behavioural problems that are typical of other addictions. Impairments of real-life interactions are also due to prolonged use of the Internet. Individuals with Internet Addiction spend more time in seclusion and are at many instances regarded as socially awkward. People who are addicted to theinternet tend to conceal the time spent on the internet thus causing distrust and disturbances in stable relationships (Young, 1999).

Several who suffer from Internet Addiction happen to create a nonline avatar or profiles where they manipulate their identities and pretend to be someone other than what they really are. Those who show low self-esteem, feelings of inadequacy, and fear of disapproval are in danger of living a secret life. Such adverse selfconceptions lead to psychological issues of depression and anxiety 
(Sherer, 1997). Even those who try to quit internet use experience withdrawal symptoms including depression, anxiety, relief, mood swings, fear, irritability, sadness, procrastination, loneliness, anger, boredom, restlessness, disturbed appetite and upset stomach. There are various physical discomfort or medical problems caused due to Internet Addiction such as dry eyes, backaches, severe headaches, eating irregularities, (such as skipping meals), failure to attend to personal hygiene and sleep disturbance (Nalwa \& Anand, 2003).

The ACE model explains the compulsive use of the internet or net compulsions. ACE is the acronym for Accessibility, Control, and Excitement.

Accessibility - convenient and easy access to the internet through digital advances has made instant access to betting, shopping, and online gaming easier. This leads to immediate gratificationthus satisfying our impulsivedemands.

Control - online activities are completely under the control of users. Personalisation of apps and privacy features makes the user feel that he or she can constantly engage in activities without anyone knowing about it.

Excitement - there is a feeling of excitement that one gets when they win a voucher for shopping, online auctions, video games or online betting. This excitement gives positive feedback thus leadingto repeated internet usage. The feeling of convenience, independence and excitement created by online activities makes the user want to do itagain.

The model explains how Internet Addiction is developed and maintained. The easy accessibility to the internet, lack of control in its usage and the pleasure experienced by using the internet altogether become the reinforcing factors of the viciousloop.

The concept of Locus of Control is currently a standout amongst the most examined factors in psychology and the other social sciences. It was introduced by psychologist Julian Rotterin 1966 (Rotter, 1966). It's a construct that is used to categorise people's basic motivational orientation and perception of the extent to which they have control over the events in their lives, which originated in Rotter's theory of Social Learning (1954). The theme is 
typically divided into two: internal and external. In simple words, internal locus signifies that the individual feels in control of events and external locus indicates that the person feels that others have the control. Individuals with an internal Locus of Control are likely to assume responsibility for their actions and are not easily affected by others' opinions. They tend to do better attaskswhen working at their own pace. On the other side, people with an external Locus of Control usually try to blame outside circumstances for their mistakes or failure and credit their achievementstoluck rather than to their own efforts. They are easily swayed by the opinions of othersand aremore likely to pay attention to the position of the opinion-holder, while people with an internal Locus $\mathrm{f}$ Control give more attention to the content of the opinion regardless of who holds it. (Feist \& Feist, 2008).

For instance, if an individual with an internal Locus of Control does poorlyin a test, she is likelyto blame either her own lack of ability or preparation for the test. By comparison, a person with an external Locus of Control will tend to explain a low grade by saying that the test was too hard or that the teacher graded unfairly.

Control locus is often regarded as an inborn element of personality. One of the assumptions of Rotter's theory is that human personality is learnt. They are coloured by the experiences that intervene and then influence perceptions. It is shaped by childhood experiences including children's relationships with their family. Children raised by parents who encouraged their autonomy and helped them learn the link between behavior and its consequences tended to have a better established internal controllocus.

Resilience, as a psychological construct is described as one's capacity to return to normal life after experiencing challenging situations. A loved one's death, work loss, disease, terrorist attacks and other traumatic occurrences are examples of difficult life experiences. It is Resilience that allows individuals to adapt well to life-changing and stressful circumstances.

While Carver (1998) considered Resilience as the capacity to bounce back from "disruptions in functioning resulting from stress appraisals," and "the ability to return to the previous level of 
functioning" (Carver, 1998), Walsh and colleagues noted that being resilient involves not just surviving and being a casualty for life, but also the ability to heal and be strengthened to live life completely (Walsh, Dawson, \& Mattingly, 2010).

Being resilient does not mean that an individual does not experience problems or distress. Emotional hurt and sorrow are prevalent among individuals who have experienced significant adversity or trauma in their life. Indeed, the path to Resilience is likely to involve significant emotional distress. Kadner (1989) conceptualized Resilience rightly as an individual's ability to make a "psycho-social come back in adversity"(Kadner, 1989). Further, Luthar defines" resilience as positive adaptation even during the times of adversity" (Luthar, 2006).

The variable focussed method to study Resilience aims at examining positive outcomes through interactions between the individual, the environment and consequent experiences (Masten \& Garmezy, 1985). At times of adversity, not everyone reacts in the same manner. Many research studies have shown that the primary factor in Resilience is caring and supportive relationships within and outside the family. Relationships that build love and trust, provide role models and promote reassurance that strengthens Resilience in a person.

The Doughnut Resilience model suggested by Worsley accounts for the ability of a person, the accessibility of funds, and the existence of adversity and environmental conditions in which a person grows (Worsely, 2015). The model demonstrates various path ways in the Resilience development process and has the potential to be a Resilience-building tool, enabling programmes, and therapeutic interventions to be underpinned by sound research.

The model structure demonstrates the interaction of internal and external variables in the development of Resilience and is represented by an internal and external circle. The internal circle represents the internal traits of the person and the external circle the external environment within which a person grows. The internal circle of the model contributes to increasing self-esteem, self-efficacy and an individual's knowledge of their accessible resources and, in conjunction, contributes to Resilience. The outer 
circle of the model, split into seven parts, addresses research that demonstrates environmental contexts where Resilience can be developed. These seven contexts are labelled-parent, skill, family, education, peer, community and money (Worsley, 2015).

\section{Rationale for the Study}

Internet Addiction is rising among emerging adults. It is an upcoming mental condition which needs a lot of studies corresponding to the degree of involvement in people's lives.Individuals between 18- 34 years of age constitutes the most active users.

Students going to college or university are considered most susceptible as they have convenient access to laptops and computer labs for various reasons (Smith et al., 2008). Apart from its benefits to the educational development of young people, the internet is also responsible for negative effects on their psychological wellbeing. It is absolutely necessary to understand the degree to which Internet Addiction can affect the psychological well- being. Itisalsoimportanttostudy the effects of the variables on Internet Addiction as it can help in formulating Internet Addiction treatment. The current study focuses on understanding the Locus of Control and Resilience in internet addicts at different levels and non-addicts.

\section{Method}

\subsection{Objectives}

1. To assess the level of Internet Addiction among young adults

2. To investigate the relationship between Internet Addiction, Locus of Control and Resilience

3. To analyse the gender difference with respect to Internet Addiction, Locus of Control and Resilience

4. To investigate the difference in the Locus of Control and Resilience with respect to different levels of Internet Addiction 
5. To study the impact of Locus of Control and Resilience on Internet Addiction of the population

\subsection{Hypotheses:}

H01: There will be no significant relationship between Locus of Control and Internet Addiction

H02: There will be no significant relationship between Resilience and Internet Addiction

H03a. There will be no gender difference in Internet Addiction

H03b There will be no gender difference in Locus of Control

H03c There will be no gender difference in Resilience

H04a There will be no significant difference in Locus of Control with respect to different levels of Internet Addiction

H04b There will be no significant difference in Resilience with respect to different levels of Internet Addiction

H05 There will be no significant impact of Locus of Control on Internet Addiction

H06 There will be no significant impact of Resilience on Internet Addiction

\section{Keywords}

Internet Addiction: It is the inability to maintain, balance or monitor internet use in relation to everyday life.

Locus of Control: It refers to an individual's perception of control which could affect the outcome of a situation.

Resilience: it is defined as one's ability to thrive in adverse situations and recover from or adjust easily to changes.

Emerging Adults: it is the transactional period from adolescence to young adulthood which includes individuals agedbetween 1825 years. 


\section{Research Design and Sample}

A comparative study with a descriptive survey method was employed to study the difference in Locus of Control and Resilience with respect to different levels of Internet Addiction. Convenience sampling technique was used and 205 adults aged between 18-25 were part of the population.

\subsection{Procedure}

Based on the objective of the study, the set of questionnaires were given to the targeted sample. 205 responses were selected. The respondents were divided into four groups based on different degrees of Internet Addiction i.e. normal, mild, moderate, and severe level of Internet Addiction. Respondents who score between 0- 19 will fall into the category of normal users, 20-49 will fall into the category of people with mild Internet Addiction and those who score between 50-79 will fall into the category of people with moderate level of Internet Addiction and those who score between 80-100 will fall into the category of people with severe Internet Addiction. With respect to the different levels of Internet Addiction, Locus of Control and Resilience will bestudied.

\subsection{Measures}

Internet Addiction Test, developed by Dr Kimberly Young (1998) is an extensively used instrument in Internet Addiction.Psychological researches with moderate to good internal consistency i.e. alpha coefficient range from 0.54 to 0.82 . It is a five-point rating scale which consists of 20 items to evaluate the respondents' level of Internet Addiction and the participants are asked to respond to them by selecting any one option from number one to five. Here, 1 indicates' Not at All', 2 indicates 'Rarely', 3 indicates' Occasionally', 4 indicates 'Often' and 5 indicates' Always'. The score on this questionnaire ranges from a minimum score of 20 to a maximum score of 100 . The total score $<20$ indicate normal users. The scores ranging from 20 to 49 indicate minimal users, while scores from 50 to 79 indicate moderate users and the scores from 80 to 100 indicate excessive users. 
The Internal-External Locus of Control Inventory (I-EInventory) was developed by Rotter (1966). This scale consists of 29 pairs of forced-choice items including 6 filler items. One item in each pair being keyed for internal control while the other for external control. One mark is given for each of the keyed choices. However, 6 filler items which are 1,8,14,19,24,27 are not included in scoring. The maximum possible score is 23 and the minimum is 0 . The reliability of this scale was estimated by two methods, namely the split half and the test-retest method, and was found to be 0.65 to 0.79 and 0.55 to 0.83 respectively.

The Brief Resilience Scale (BRS) (Smith et al., 2008) is a 6-item measure of Resilience to measure the ability to recover from stress and adversity. Responses are graded on a 5-point Likert scale spanning from Strongly Disagree (1) to Strongly Agree (5). To assess the score, scores of items 2, 4 and 6 are reversed. Reversing a score is achieved by exchanging the original value of an item by its opposite value: a score of 1 turns in to a score of 5 , a score of 2 turns in to a 4 and so on. Then, just add up all the scores of the individual items. A weighted score can be calculated by dividing the total score by the number of items, in this case, 6 . The higher the mean BRS score, the more resilient the respondent is. BRS is a single factor scale.

\subsection{Results Objective: To assess the level of Internet Addiction}

Table 1: Frequency and Percentage of different levels of Internet Addiction

\begin{tabular}{lcc}
\hline & Frequency & Percent \\
\hline Normal users & 14 & 6.8 \\
Mild & 114 & 55.6 \\
Moderate & 59 & 28.8 \\
Severe & 18 & 8.8 \\
Total & 205 & 100 \\
\hline
\end{tabular}

*primary source

Table 1 shows the distribution of the participants on the basis of the level of Internet Addiction. Out of 205 respondents, 14 respondents $(6.8 \%)$ were normal users, 114 respondents $(55.6 \%)$ had a mild level of Internet Addiction, 59 respondents $(28.8 \%)$ had a moderate level of Internet addiction and 18 respondents $(8.8 \%)$ had severe levels of 
Internet Addiction. The level is highest for mild levels of Internet Addiction accompanied by moderate levels of Internet Addiction followed by severe levels of Internet Addiction. Least is the frequency of normal users.

Objective: To investigate the relationship between Internet Addiction, Locus of Control and Resilience

H01 There will be no significant relationship between Locus of Control and Internet Addiction

H02 There will be no significant relationship between Resilience and Internet Addiction

Table 2: Pearson correlation between Internet Addiction, Locus of Control and Resilience

\begin{tabular}{lccc}
\hline & Internet Addiction & Locus of Control & Resilience \\
\hline Internet addiction & 1 & & \\
Locus of Control & $.157^{*}$ & 1 & \\
Resilience & $-.219^{* *}$ & -.029 & 1 \\
\hline
\end{tabular}

** $p<0.01 * p<0.05$

Table 2 shows the association between the variables Internet Addiction, Locus of Control and Resilience. It can be seen that there is a significant correlation between Internet Addiction, Locus of Control and Resilience. The relationship between Internet Addiction and Locus of Control has been found to be statistically significant with weak positive correlation $(\mathrm{r}=.157, \mathrm{p}<0.05)$. The hypothesis which stated that there will be no significant relationship between Locus of Controland Internet Addiction was rejected. Therefore, the higher the score of Locus of control, the higher will be the level of Internet Addiction. That is, a high score of Locus of Control indicates the external Locus of Control. Thus, the external Locus of Control is positively associated with a high level of InternetAddiction.

Also, the relationship between Internet Addiction and Resilience has been found to be statistically significant with a weak negative correlation $(\mathrm{r}=-.219, \mathrm{p}>0.01)$. This indicates that lower the Resilience level, greater will be the level of Internet Addiction. One 
of the reasons why the internet is excessively used is because of its buffering effects from stressful events. Internet usage may increase during times of stress leading to increased addiction in people with low Resilience. Thus, the hypothesis of the study which stated that there will be no significant relationship between Resilience and Internet Addiction was rejected.

Objective: To analyse the gender difference among Internet Addiction, Locus of Control and Resilience

H03a. There will be no gender difference in Internet Addiction

H03b There will be no gender difference in Locus of Control H03c There will be no gender difference in Resilience

Table 3: The mean differences among the gender in Internet Addiction, Locus of Control and Resilience

\begin{tabular}{llcc}
\hline & Gender & Mean \pm SD & df $=203$ \\
\hline \multirow{3}{*}{ Internet Addiction } & Male & $49.05 \pm 20.809$ & \\
& Female & $41.81 \pm 19.674$ & $2.560^{*}$ \\
Locus of Control & Male & $11.49 \pm 3.082$ & \\
& Female & $11.43 \pm 3.420$ & .139 \\
& Male & $18.79 \pm 3.931$ & \\
Resilience & Female & & -.330 \\
\hline
\end{tabular}

Table 3 shows the mean comparison between males and females for Internet Addiction, Locus of Control and Resilience. The results suggest a significant mean gender difference in Internet Addiction $(t=2.560$, significant at 0.05 level). The mean of males, 49.05 , was found to be significantly higher than that of females at 41.81 . Therefore, the hypothesis stating that there will be no gender difference in Internet Addiction is rejected.

In other variables, there was no significant gender difference observed between the mean values of both males and females. Therefore, the hypotheses stating that there will be no gender difference in Locus of Control and Resilience isaccepted.

Objective: To investigate the difference in Locus of Control and Resilience with respect to different levels of Internet Addiction 
H04a There will be no significant difference in the Locus of Control and Resilience with respect to different levels of Internet Addiction

H04b There will be no significant difference in Resilience with respect to different levels of Internet Addiction

Table 4: showing the mean difference among the levels of Internet Addiction for variables Locus of Control and Resilience

\begin{tabular}{llccc}
\hline Variable & $\begin{array}{c}\text { Classification of } \\
\text { Internet Addiction }\end{array}$ & Mean \pm SD & $\begin{array}{c}\text { F ratio } \\
\mathrm{df}=3,201\end{array}$ & Post hoc \\
\hline \multirow{2}{*}{ Locus of } & Normal users (G1) & $11.64 \pm 3.342$ & & \\
Control & Mild (G2) & $11.02 \pm 3.456$ & & -- \\
& Moderate (G3) & $11.88 \pm 2.889$ & 1.985 & \\
& Severe (G4) & $12.72 \pm 2.562$ & & \\
& Normal users (G1) & $21.43 \pm 3.631$ & & \\
Resilience & Mild (G2) & $19.19 \pm 3.858$ & & \multirow{2}{*}{ G1>G3, G4 } \\
& Moderate (G3) & $18.03 \pm 3.454^{*}$ & $4.016^{*}$ & \\
\hline
\end{tabular}

Table 4 shows the difference in the mean of Locus of Control and Resilience within different levels of Internet Addiction. The results suggest that there were significant differences in Resilience among the levels of Internet Addiction. The post hoc test reveals that in Resilience, the mean of normal users (mean $=21.43$ ) is significantly higher than that of moderate and severe levels of Internet Addiction. This indicates that higher the Resilience levels, lower was the level of Internet Addiction. Thus, rejecting the hypothesis which stated that there will be no significant difference in Resilience with respect to different levels of Internet Addiction. In the other variable, Locus of Control, there was no significant mean difference in the levels of Internet Addiction. Therefore, the hypothesis stating that there will be no significant difference in the Locus of Control with respect to different levels of Internet Addiction is accepted.

Objective: To study the impact of Locus of Control and Resilience on Internet Addiction of the population

H05 There will be no significant impact of Locus of Control on Internet Addiction

H06 There will be no significant impact of Resilience on Internet Addiction 
Table 5: showing multiple regression for Internet Addiction

\begin{tabular}{|c|c|c|c|c|c|c|c|c|}
\hline \multirow[t]{3}{*}{ Variables } & \multirow[t]{3}{*}{ B } & \multirow[t]{3}{*}{$\mathrm{F}$} & \multirow[t]{3}{*}{$\mathrm{df}$} & \multirow[t]{3}{*}{$\mathrm{P}$} & \multirow[t]{3}{*}{$\mathrm{R}^{2}$} & \multirow[t]{3}{*}{$\begin{array}{l}\text { Adj } \\
\mathrm{R}^{2}\end{array}$} & \multicolumn{2}{|c|}{$\begin{array}{l}95.0 \% \text { Confidence } \\
\text { Interval for B }\end{array}$} \\
\hline & & & & & & & Lower & Upper \\
\hline & & & & & & & bound & Bound \\
\hline Constant & 56.308 & & & .000 & & & 39.194 & 73.423 \\
\hline $\begin{array}{l}\text { Locus of } \\
\text { Control }\end{array}$ & .950 & 7.682 & 2,202 & .028 & .071 & .061 & .105 & 1.796 \\
\hline Resilience & -1.154 & & & .002 & & & -1.872 & -.435 \\
\hline
\end{tabular}

Table 5 shows multiple regression. The independent variable that is, Locus of Controland Resilience in the standard model are significantly predictive of the dependent variable Internet Addiction, explaining the significance $26.6 \%$ of the variance in the analysis, $\mathrm{F}(\mathrm{df} 2,202)=7.682 \mathrm{p}<.001, \mathrm{R}^{2}=0.71$. The absolute variable of $\beta$ indicated the order of importance of the independent variable. On examining, the contributions made by the independent variables in the model,it was found that the scores received from the Locus of Control made the biggest contribution with the value $\mathrm{p}=(95 \%$ of confidence interval $0.105,1.796)$ followed by Resilience with the value $\mathrm{p}=0.02$ (95\% of confidence interval-1.872,-.435). Based on multiple regression analysis, the equation obtained is Internet Addiction $=56.308+.950-1.154=56.104$.

Results show that the Locus of Control and Resilience contribute to $26.6 \%$ variance in the analysis indicating that both variables have a significant impact on Internet Addiction. The Locus of Control positively predicts Internet Addiction whereas Resilience negatively predicts Internet Addiction.

The Locus of Control reflects an individual's active control over internet usage. Individuals with a low score in Locus of Control i.e. internal Locus of Control will actively try to keep control overthe time they spend on the internet and the purpose as well. This indicates that they have less probability of developing Internet Addiction (Agaj, 2016) as they can monitor, cut down or stop internet use at will (Chak \& Leung, 2004). People with an external Locus of Control failed to control their internet use. Resilience was found to be negatively predicting Internet Addiction in the present 
study. This indicates that individuals with low Resilience might have a greater risk of developing Internet Addiction.

\section{Conclusion}

In conclusion, the internet, when used without control causes dependency, addiction and chronic conditions. Several facts related to Internet Addiction were highlighted in this study particularly the levels of Internet Addiction and the role of Locus of Control and Resilience in it. It was found that the frequency is highest for mild levels of Internet Addiction, followed by moderate levels of Internet Addiction and severe levels of Internet Addiction. The least is the frequency of normal users among emerging adults. The weak positive correlation of Internet Addiction with the Locus of Control and weak negative correlation with Resilience found inthe study supports the facts that these two variables can be used in training people with compulsive internet use and reducing the frequency of Internet Addiction. The study clearly shows thathigher the level of Resilience, lower was the level of Internet Addiction. Therefore, the Locus of Control and Resilience were shown to be potential predictors of InternetAddiction.

\subsection{Limitations}

- The study was restricted to particular geographical areas such as Bangalore, Punjab and Kerala.

- No attempt was done to study the various sites accessedby different genders and their purpose ofuse.

- Self-report ratings of Internet Addiction, Locus of Control and Resilience are similarly vulnerable to over or underreport depending on the individual's level of selfawareness, prone to participant responsebias

- The Internet Addiction Test was the only validated scale but it was not up to date as many questions did not match the present usage patterns, which could have pointed more towards addiction. Internet addiction was studied from the addiction point of view of emerging adults. 
- No attempts were made to study the personality correlates of Internet Addiction.

- The data was collected one time and no attempt was made to intervene in the selected sample

- Responses could have been influenced by the short comings of any paper and pencil assessments such as social desirability, response bias and carelessness, positive and negative faking tendencies.

\subsection{Implication}

The findings of the study will provide additional information and understanding in the field of Internet Addiction as a new mental disorder to various mental health professionals and research scholars. The study will provide a better understanding of the factors (like the Locus of Controland Resilience in the present study) that make a person prone to excessive use of the internet leading to Internet Addiction. It will help to understand the interplay of the two variables and consequences of Internet Addiction among emerging adults. It will also support the global consensus to include internet-related disorders in the upcoming version of ICD-11or text revisions of DSM. The results of this study are expected to improve the perception of InternetAddiction.

With the evidence of research, the two variables can be used as predictors of Internet Addiction. Thus, by studying the difference in the Locus of Control and Resilience with respect to different levels of Internet Addiction, we can formulate interventions aiming at changing the Locus of Control and increasing the Resilience. Therefore, the results of this study can be fruitful for psychologists, educational consultants and mental health professionals to formulate preventive measures and deal with mental health issues related to Internet Addiction. It can be used to guide intervention programmes in schools and colleges. This is important even for clinicians who need to develop more focused intervention programmes not only for adolescents but also for emerging adults. 


\section{References}

Agaj, D. (2016). The impact of the components of the locus of control in internet addiction, case of Albania. American Scientific Research Journal for Engineering, Technology, and Sciences (ASRJETS), 18(1), 40-44.

Alexander, B. K., \& Schweighofer, A. R. F. (1988). Defining "addiction." Canadian Psychology/Psychologie Canadienne, 29(2), 151-162. https:// doi.org/10.1037/h0084530

Beard, K. W. (2002). Internet Addiction: Current Status and Implications for Employees. Journal of Employment Counseling, 39(1), 2.

Carver, C. S. (1998). Resilience and thriving: issues, models, and linkages. Journal of Social Issues, 54(2), 245-266. https://doi.org/10.1111/00224537.641998064

Chak, K., \& Leung, L. (2004). Shyness and locus of control as predictors of internet addiction and internet use. Cyberpsychology $\mathcal{E}$ Behavior: The Impact of the Internet, Multimedia and Virtual Reality on Behavior and Society, 7(5), 559-570. https://doi.org/10.1089/cpb.2004.7.559

Feist, J., \& Feist, G. J. (2008). Theories of personality (7th ed.). McGraw- Hill.

Greenfield, D. N. (1999). Psychological characteristics of compulsive internet use: a preliminary analysis. Cyberpsychology $\mathcal{E}$ Behavior: The Impact of the Internet, Multimedia and Virtual Reality on Behavior and Society, 2(5), 403412. https:/ / doi.org/10.1089/cpb.1999.2.403

Griffiths, M. D. (1998). Internet addiction: Does it really exist? In J. Gackenbach (Ed.), Psychology and the internet: intrapersonal, interpersonal and transpersonal applications, pp. 61-75. New York: Academic Press, 61-75.

Kadner, K. D. (1989). Resilience. Responding to adversity. Journal of Psychosocial Nursing and Mental Health Services, 27(7), 20-25.

Kandell, J. J. (1998). Internet Addiction on Campus: The Vulnerability of College Students. CyberPsychology $\mathcal{E}$ Behavior, 1(1), 11-17. https:// doi.org/10.1089/cpb.1998.1.11

Kujawski, M. (2018, February 20). Global internet statistics for 2018. Retrieved February 1, 2019, from Navigating Digital Disruption website: http:/ / www.mikekujawski.ca/2018/02/20/2018-global-internetstatistics-update/

Luthar, S. (2006). Resilience in Development: A Synthesis of Research across Five Decades. Risk, Disorder, and Adaptation, 739-795. https://doi.org/10.1002/9780470939406.ch20

Miller, D., \& Slater, D. (2001). The internet: An ethnographic approach. Retrieved from http://www.amazon.ca/exec/ obidos/ redirect? tag=citeulike0920\&path=ASIN $/ 1859733891$

Morrissey, J., Keogh, B., \& Doyle, L. (2008). Psychiatric/ mental health nursing: An Irish perspective. Gill \& Macmillan.

Nalwa, K., \& Anand, A. P. (2003). Internet addiction in students: a cause of concern. Cyberpsychology $\mathcal{E}$ Behavior: The Impact of the Internet, Multimedia 
and Virtual Reality on Behavior and Society, 6(6), 653-656. https:// doi.org/10.1089/109493103322725441

Potenza, M. N. (2006). Should addictive disorders include non-substancerelated conditions? Addiction (Abingdon, England), 101 Suppl 1, 142-151. https:/ / doi.org/10.1111/j.1360- 0443.2006.01591.x

Rotsztein, B. (2003, April 10). Problem Internet use and locus of control among college students: Preliminary findings. The 35th Annual Conference of the New England Educational Research Organizaion, Portsmouth, New Hampshire. https://www.rotsztein.com/ downloads/ internetresearch.pdf

Rotter, J. B. (1966). Generalized expectancies for internal versus external control of reinforcement. Psychological Monographs: General and Applied, 80(1), 1-28. https:/ / doi.org/10.1037/h0092976

Shaw, M., \& Black, D. W. (2008). Internet addiction. CNS Drugs, 22(5), 353365. https:/ / doi.org/10.2165/00023210-200822050-00001

Sherer, K. (1997). College life on-line: healthy and unhealthy Internet use. Journal of College Student Development, 38(6), 655-665.

Smith, B. W., Dalen, J., Wiggins, K., Tooley, E., Christopher, P., \& Bernard, J. (2008). The brief resilience scale: assessing the ability to bounce back. International Journal of Behavioral Medicine, 15(3), 194200.https:/ / doi.org/10.1080/10705500802222972

Tukaram, B. A. (2017). Internet Addiction ans Its effects on children of Marathi Medium School- A case study. Shri Jagdishprasad Jhabarmal Tibrewala University, Vidyanagari, Rajasthan. http:// shodhganga.inflibnet. ac. in:8080/jspui/handle/10603/200477

Turner, A. (2015b). Generation Z: Technology and Social Interest. The Journal of Individual Psychology, 71(2), 103-113. https:// doi.org/ 10.1353/jip.2015.0021

Walsh, W. A., Dawson, J., \& Mattingly, M. J. (2010). How are we measuring resilience following childhood maltreatment? is the research adequate and consistent? What is the Impact on research, practice, and policy? Trauma, Violence, $\mathcal{E}$ Abuse, 11(1), 27-41. https://doi.org/10.1177/1524838009358892

Worsely, L. (2015, January). The resilience doughnut: Combining strengths to survive. Retrieved August 3, 2019, from Research Gate website: https://www.researchgate.net/ publication/ 298718942_ The_resilience_ doughnut_Combining_strengths_to_survive

Worsley, L. (2015). The resilience doughnut: The secret of strong kids. Australian eBook Publisher.

Young, D. K. S. (1999). Internet Addiction: Symptoms, Evaluation, and Treatment. Innovations in Clinical Practice, 17, 17. 